\title{
An Analysis of Design and Equipment of Field Waste-Free System in Drilling
}

\author{
Hongbin Liu ${ }^{1}$, Qiyun Cheng ${ }^{2}$ \\ (School of Mechatronic Engineering, Southwest Petroleum University, Chengdu 610500, China)
}

\begin{abstract}
With the development of drilling technology, the composition of drilling fluid gains its complexity, which thenbrings about adramatic increase of drilling waste, and severe environmental pollution as well. We conducted the survey and analysis of domestic waste disposal technology of solid control equipment. The result shows that waste disposal technologies developed both at home and abroad are not flawless, and solid control equipment is defective as well. We are desperate for the development and improvement ofa new drilling field waste-free system to conduct a secondary purification for waste after being separated by solid control system, recycle the useful drilling fluid, and conduct safe, drying and molding process for drilling cuttings, by which the drilling cost can be reduced, the operation environment can be improved, and the environmental requirements can be met.
\end{abstract}

Keywords: Field waste-free; Solid control system; Technological process; Compression moulding; Dragging working

\section{Introduction}

During oil drilling, the drilling fluid solid control system separate the drilling fluid, which is full of rock debrises, into liquid phase and solid phase. The liquid phase, after being slightly disposed, gets back to the drilling fluid circulation, while the solid phase contains a large number of harmful substances, which contain much oil and water. The direct discharge may cause enormous waste of resources, and severe environmental problems as well. The further research and improvement of field waste-free system will be needed to effectively control harmful solid phase, and make it recyclable. Present situation and existing problems of waste management technology home and abroad

1) Direct discharge: This method has been limited due to the increasing chemicaladditives in drilling fluid and stricter requirements in global environmental standards.

2) Backfilling: Although cheap and widely applicable, it will do harm to the underground water and surrounding soil.

3) Farming composing: It can improve the soil structure and fertilizer efficiency, and it is easy to operate. However, despite the huge amount of work it needs, farming composing is not applicable when it comes to waste drilling fluid with strong bio-toxicity.

4) Chemical consolidation and solidification: As a method of no toxicity, it is widely applicable, with cheap raw materials, low water solubility and permeability, long stable period, and good performance.

5) Decentralized processing: It is a cheap method which is able toimprove soil, but it cannot be widely applied, and it fails to meet the current environmental protection standards.

6) Injection into formation: It is cheap, but it may contaminate the underground water and oil layer.

7) Incineration: Incineration is a clean processing method, but it is energy-consuming.

8) Thermal distillation: It has a high recovery for oil, and it has been used commercially on a large scale. However, it is costly, unsafe, and energy-consuming.
9) Microorganism processing: This means to cultivate degrading bacteria, and then choose those with better degrading capability to degrade the waste drilling fluid. It is an effective method, which can also avoid secondary pollution, but it is sensitive to environment so its application is limited.

10) Extraction: This means to clean oily sands with organic solvent, by which then crude oil can be extracted. During the operation, the organic solvent is recycled. However, it is under great demand, which further cause technical and management problems, coupled with the high disposal cost, lead to the limited application.

11) MTC technology: This means to combine the waste drilling fluid with slags, then add other additives to turn it into cement paste. Dagang oilfield used various cement paste systems to conduct someten field applications, all of which got good results.

\section{Current solid control system and the existing problems}

A 4-level clarification system, namely, vibrating screen, desander, desilter, and centrifuge, is used in the current solid control system. At some drilling sites, degasifier is also added to form a 5-level clarification system. Here is the process flow diagram 1 :

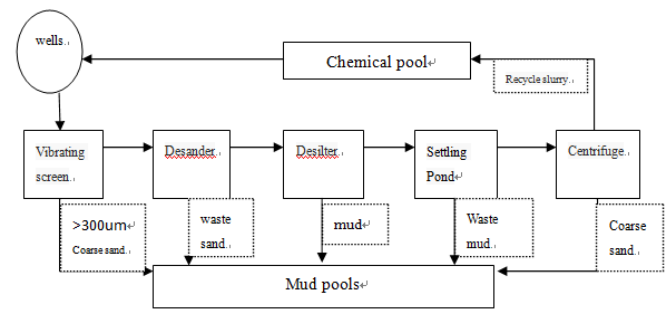

Figure 1: The System of Solid Control Process Flow

There are 3 major problems in this system: firstly, due to the different principles and structures of the mentioned machines, the granularities of solid particles which they separate range from each other, and the solid moisture

Volume 5 Issue 6, June 2016 www.ijsr.net 


\section{International Journal of Science and Research (IJSR) \\ ISSN (Online): 2319-7064}

Index Copernicus Value (2013): 6.14 | Impact Factor (2015): 6.391

content is relatively high after every separation, which leads to the waste of drilling fluid and environmental pollution in the subsequent landfill process; secondly, solid control equipment is bulky, and not easy to move; thirdly, solid control equipment is not properly installed and used in many drilling sites. In such cases, the solid control effect is not up to scratch, and the vibrational frequency and intensity are influenced as well, both of which accelerate the aging of equipment, and lead to the failure in meeting the demand of drilling fluid property. Besides, the subsequent purification is thus under great pressure, and the whole solid control effect is reduced. So, it is of great urge to design a new environmental-friendly process to improve the recovery fordrillingsludge.

\subsection{Vibrating screen}

As the first-level solid control equipment of drilling fluid disposal, the vibrating screen plays a vital role in treating the harmful solid particles in drilling fluid. There are 3 major types of vibrating screens generally used in China, namely, single-shaft inertia vibrating screen, double-shaft vibrating screen, and multi-shaft vibrating screen. The existing problems are as follows: (1), lack of knowledge of the structure itself; (2), slow progress in large-sized vibrating screen; (3), lack of knowledge of relations between technical parameters of high frequency vibrating screen; (4), failure in meeting the demand of material structural intensity. The future research on vibrating screen should be focused on the structural intensity design, the shape design of screen, and the new vibration mode design.

\subsection{Degritting and desilting all-in-one machine}

Sludge cleaner plays a transitional role in the whole drilling fluid solid control system. Using the new all-in-one machine can separate solid phase from drilling fluid which vibrating screen is not able to, and provide support for the efficient operation of centrifuge.

\subsection{Centrifuge}

Centrifuge is indispensable as the last-level purification equipment in the traditional solid control system. Middle-low speed decanter centrifuge is generally used in operation field to conduct the solid-liquid separation, with the separation size between 2 and $74 \mu \mathrm{m}$. The higher revolving speed it gains, the smaller the separation size will be. The moisture content of solid phase after separation is about $20 \%$. The solid phase, after being processed up to standard, is disposed through landfill or incineration. There are still many problems in the field application of centrifuge, like small handling capacity, high moisture content of solid phase after separation, high possibility of getting stuck in dealing with drilling fluid of high density, and the intelligent control of revolving speed.

\section{The process design of field waste-free treatment of drilling fluid}

\subsection{The process design of field waste-free}

The successive equipment of field waste-free system: vibrating screen, degritting and desilting all-on-one machine, middle-speed centrifuge, cutting dryer, high-speed centrifuge, dosing device, and molding unit. The auxiliary equipment: auger conveyor, vibrating funnel, and stirrer. Here is the detailed process flow diagram 2:

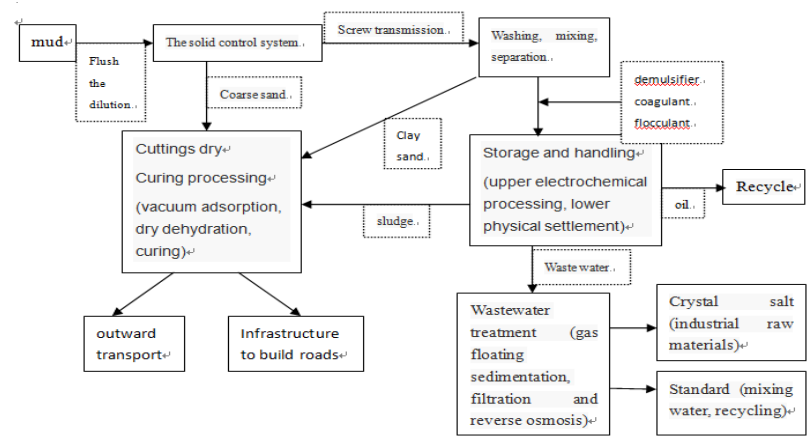

Figure 2: The Process of Mud does not Fall to the Ground

\subsection{The key equipment and the operating principles}

\subsubsection{Cuttings dryer}

Like the continuous working single-stage vertical scraping centrifuge, cuttings dryer does the solid-liquid separation by imposing centrifugal force. Then sieve basket isolates the outlier. The gap of sieve basket can be set between 0.2 to $0.5 \mathrm{~mm}$ according to the field situation and property of drillingsludge.

Treating process of internal materials in cuttings dryer: after getting into the feeding inlet, drilling cuttings are dispersed by distribution plate, then they enter the space between sieve basket and helix to dehydrate. Under the action of revolving speed 1000RPM and separation factor 500, liquid phase and small particles (centrifugal liquid) penetrate material layer and sieve basket, flow along the upper cover into the collecting tank on the machine base, and then get discharged through drain pipes on the both sides of machine base. The solid fraction of cuttings remain at the inner side of sieve basket. Because there is a speed discrepancy between rotor blade and sieve basket, rotor blade scratches the cuttings from sieve basket, and convey them to the bottom of sieve basket, thus discharging cuttings into the material receiving funnel or the bottom auger conveyor. This is a continuous process. Here is the working diagram 3: 


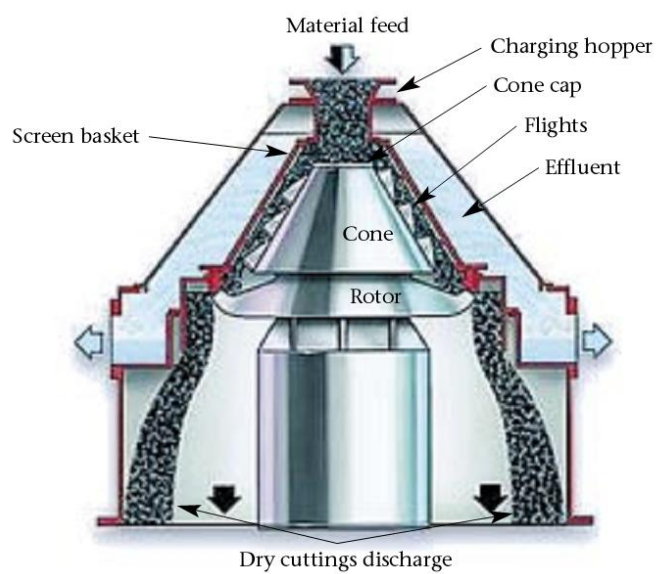

Figure 3: Working Principle of the Dryer

Cuttings dryer is the key equipment in oil drilling waste disposal. The moisture content of the solid phase separated by cuttings dryer is about $5 \%$, which dramatically improves the recycle utilization rate of drilling fluid. It is of great benefit both economically and socially.

\subsubsection{Press filtration forming device}

The operating principle of press filtration forming device is similar to that of brick machine. They both mold particles with scattered solid phase through high pressure between upper and lower stampers. It is composed of mixing drum, filter pressing device, brick-unloading device, and machine body. It is able to mix, mold, and unload bricks. Meanwhile, it is compact and environmental-friendly. The device structure is showed in diagram 4 and 5:

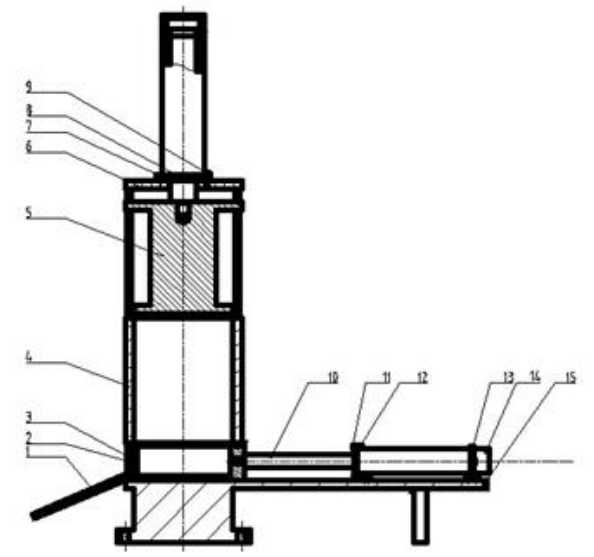

Figure 4: The Structure of Suppression

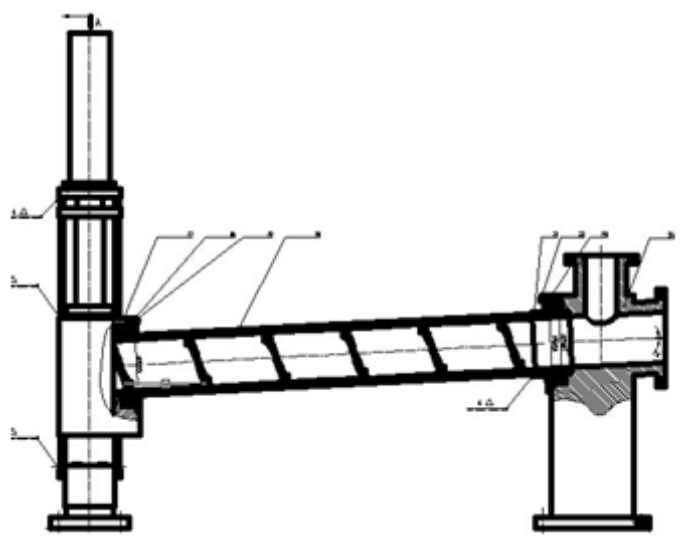

Figure 5: mechanism Stirring conveying

During operation, the solid particles of drilling fluid and adhesive enter into mixing drum, and then they are conveyed to the lower stamper by the rotation of the inner helix in mixing drum. The whole process is completed with the stamper reaching the targeted place from the top position. In the process, a little water oozes from solid particles of drilling fluid, which then enters filter cone from filter screen and gets collected. When the molding is complete, the filter cone moves rightwards by hydraulic pressure, and stamper moves downwards to fall bricks on the plate. At last, filter cone moves leftwards to convey the molded bricks. The return travel of upper stamper and that of filter cone go simultaneously, thus the consecutive production can be realized.

\subsubsection{Vibrating funnel}

Unlike other machines which suffer feeding difficulty and congestion, vibrating feeding funnel make sure the continuous and even feedingprocess without many manual operations. Besides, there is pneumatic or hydraulic butterfly bumper at the exit of vibrating funnel, which can control the size of feeding materials conveyed by auger conveyor. The whole set of system can be used at intervals to preserve energy. The vibrating funnel is composed of stand, funnel body, and shock excitation electric engine. It has a simple structure and is easy to move with pulley.

\subsubsection{Mobile crowbar truck}

The designation of mobile crowbar truck is to combine drying, molding and transporting all together to effectively conduct after treatment of drilling cuttings without manual loading. The mobile crowbar truck is able to move waste disposal system entirely, which is compact, flexible, and cost-saving.

\section{System Evaluation}

Compared with its counterparts, the drilling field waste-free system has features as follows:

1) It solves the feeding difficulty and congestion with the use of vibrating funnel.

2) The solid phase separated by centrifuge can be recycled to dryer where it undergoes a secondary treatment, by which the high oil content of solid phase separated by 


\section{International Journal of Science and Research (IJSR) \\ ISSN (Online): 2319-7064}

Index Copernicus Value (2013): 6.14 | Impact Factor (2015): 6.391

counterparts and difficulty in collection can be avoided.

3) The press filtration forming device is used at the end of system, which can mold dry cuttings separated by cutting dryer automatically, by which easier transportation, better automation, less staff and labor can be achieved.

4) The field waste-free of drilling cuttings is realized by the system, thus meeting the requirements of clean production in drilling field.

5) Centralized control system is used, with all machines to be manufactured by one or two control cabinet, thus achieving comfortable operation, simple interface, easier handling and better automation. No staff is needed when the system is started, because all parts will be executed according to the set program.

6) Unlike its counterparts, lifting equipment is included in this system, which makes it easier to maintain.

\section{The analysis of social benefit and market prospect}

\subsection{Social benefit}

The drilling field waste-free disposal system not only saves cost, but meets the requirements of new environmental protection law and drilling technology, thus enhancing the competence of petroleum equipment enterprises in domestic market, and promoting social harmony and stability. The social benefit is achieved in environmental protection. The effective recycling of drilling cuttings, other than the traditional direct discharge, backfill, and burying, makes sure soil, field and underground water will not be polluted any more, thus protecting the health of animals, plants and human beings. Besides, it lays a sound foundation for sustainable development both environmentally and economically.

\subsection{The analysis of market prospect}

With the implementation of new environmental protection law and promotion of new drilling technology, new requirements will be put forward for the disposal of drilling waste, especially the development of shale gas and other unconventional gas and oil make new demand for all-level solid control equipment, which has barely been met at present by the drilling and cuttings all-in-one disposal equipment yet. With regards to innovation, the field waste-free system is compact and creative, which can fast locate and move so as to realize the all-in-one process of drying, molding and transporting, thus solving the problem of waste being heaped in drilling field for a long time and turning waste into resource according to the national policy. Economically speaking, the traditional and simple disposal method will disappear, with the method of economic value taking over it. By this, solid waste emissions will be dramatically reduced in oil and natural gas exploration, which leads to a more economical-friendly drilling to in accordance with the economic and social development.

\section{Conclusions and Suggestions}

1) The use of new field waste-free system will avoid digging mug pits to store wastes and prevent waste drilling sludge from infiltrating into stratum.

2) It will realize the recycling of wastes to achieve optimal configuration with zero emission and pollution.

3) The system has a simple structure and small occupied area. It is easy to move, which saves costs and improve operation efficiency.

4) There is no variety in domestic waste disposal methods, especially in the research of waste disposal equipment. In the future, the development of equipment should be focused, with the priority of integration and intellectualization.

5) We have no real-time monitoring of the composition of drilling sludge yet. We should promote the research in this area to make the system smarter, thus automatic production can be achieved.

\section{References}

[1] Zhao Xionghu, Wang Fengchun. The progress in research of disposal of waste drilling fluid $[\mathrm{J}]$. Drilling Fluid\& Completion Fluid, 2004.21 (2):44-45.

[2] AnWenzhong, Chen Jianbing, Mu Xiaojun, Zhang Binhai, Xu Yongkang. Drilling cuttings re-injection and its first application in domestic oil field $[\mathrm{J}]$. Petroleum Drilling Techniques,2003,31(1):22-25.

[3] Abdullah AI-Suwaidi, Christian Hun. Comprehensive Solutions to Drilling waste Management[C].SPE88673, 2004.

[4] Liu Yucheng, Wu Mian, Chen Mingyan. The progress of and outlook for the technical research in solid disposal of drilling waste sludge $[\mathrm{J}]$. Environmental Science \& Technology, 2010,33(6):534-537.

[5] R Sorheim. Oily Drill Cuttings From Waste to Resource[C]. SPE 61273, 2000.

[6] Sirevag G, Bale A. An Important Method for Grinding and Reinjecting of Drill Cuttings[C]. IADC Drilling Conference, 1993.

[7] Wu Liang, Han Zeng, Chen Yu, Wang Xinxin, An Wei. Sketch of disposal methods of synthetic-based sludge well completion waste [C]. The proceedings of academic annual conference of Chinese society of environmental sciences (Volume 5). 2013:5506-5511.

[8] Ntukidem R, Omonigho R. Anighoro S. ThermalDesorption as an Alternative to Cutting Reinjection in Niger Delta Waste Management Operations[C]. SPE 77556, SPE Annual Technical Conference and Exhibition, San Antonio, Texas, 2002.9.

[9] Li Lun. Treatment measures of waste drilling fluids in Daqing Oil Field [J]. Standard and Quality of Chinese Petroleum and Chemical Industry, 2013(3):85.

[10] Yang Hongqi, Zhang Kejian, Yang Guangguo. The application of slags MTC technology in adjustment well and well cementation in Dagang Oil Field [J] West-China Exploration Engineering. 2009.(6):54-56.

[11]Dong Huairong, Li Zongqing, Li Qin, Guo Zhen, Fu 


\section{International Journal of Science and Research (IJSR) \\ ISSN (Online): 2319-7064}

Index Copernicus Value (2013): 6.14 | Impact Factor (2015): 6.391

Guangmeng, Chen Zhili. The status quo and development tendency of solid control system technology of drilling fluid [j]. West-China Exploration Engineering. 2015(11):49-52.

[12]Zhang Xiaodong, He Shi, Gou Ruyi, Zhu Xiaofeng, Zhang Ye. Discussion of rationality of the set of drilling fluid solid-control system in extradeep well [J]. Oil Drilling\& Production Technology. 2013(6):52-54.

Volume 5 Issue 6, June 2016 www.ijsr.net 